\title{
EL NIÑO DE LA BOLA Y LA FISIOLOGÍA DE LA NOVELA DECIMONÓNICA (I)
}

Eva F. FLORENSA

University of Pennsylvania

A Russell P. Sebold, con admiración y amistad

Tras varios años de viajes por Europa y América, vuelve a su ciudad natal Manuel Venegas, conocido por todos con el sobrenombre de "el Niño de la Bola". Regresa para contraer matrimonio con Soledad, hija del usurero que causó la ruina y muerte de Don Rodrigo Venegas, padre de Manuel. Al llegar a la población, la joven se encuentra ya casada y es madre de un hijo. Manuel - a causa de este hecho- cree enloquecer y promete venganza, pero Don Trinidad Muley, el cura que le recogió cuando muriera su padre, le desengaña de tal idea y consigue que su ahijado abandone el lugar. "Vitriolo", farmacéutico, librepensador y ateo, en otro tiempo rechazado por Soledad, ve en Venegas el medio de vengarse del pasado desprecio de ella; logra que el loco enamorado regrese de nuevo y provoca así un fin trágico: Manuel mata a su amada y el marido de ésta a "el Niño de la Bola".

A simple vista, El Niño de la Bola de Don Pedro Antonio de Alarcón es una historia romántica de amor imposible y trágico. La novela presenta todos los elementos de este tipo de narraciones: joven héroe en conflicto consigo mismo y con el mundo, amor frustrado por restos de antiguas rencillas entre la familia de los enamorados, acción movida por un destino adverso y absurdo, y final sangriento. Sin embargo, ¿es El Niño de la Bola una novela romántica? 
El segundo Romanticismo y el Postromanticismo' se extienden aproximadamente desde 1830 hasta 1870. El llamado Realismo hunde sus raíces incluso antes de 1860 y el Naturalismo penetra desde 1877, dándose su plena efervescencià de los años 1880 a 1883 . El Niño de la Bola se publica en 1880 . Desde esta perspectiva cronológica, parece lícito afirmar que nuestra novela está muy lejos del pleno Romanticismo y demasiado cerca del Realismo y del Naturalismo.

La novela permite una tercera aproximación. A pocas páginas de su inicio, el narrador se refiere a la historia que va a contar en los siguientes términos:

Ahora bien, amigos lectores: el primer cuadro del drama romántico de chaqueta y rigurosamente histórico, aunque no político, que voy a contaros (tal y como aconteció, y yo lo presencié, entre la extinción de los frailes y la creación de la Guardia Civil, entre el suicidio de Larra y la muerte de Espronceda, entre el abrazo de Vergara y el pronunciamiento del general Espartero, en 1840, para decirlo de una vez)...2

Así pues, según el propio redactor de los sucesos, El Niño de la Bola es un "drama romántico de chaqueta"; y, si tal como él mismo afirma ("que voy a contaros tal y como aconteció, y yo lo presencié"), su intención es reconstruir fielmente ("cuadro rigurosamente histórico") los acontecimientos y el marco en que se desarrolló el "drama", entonces la novela tendría que reproducir la vida social y psíquica del Romanticismo, ya que toda la acción tiene lugar "en 1840".

La opinión crítica de los contemporáneos de Don Pedro Antonio (Manuel de la Revilla, Leopoldo Alas, Juan Valera, Benito Pérez Galdós, etc.) oscurece todavía más la dilucidación de la naturaleza romántica o realista de El Niño de la Bola. De los numerosos estudios que en su momento se dedicaron a Alarcón y a su obra, quizá el más avispado sea el que, en $L a$ cuestión palpitante, Emilia Pardo Bazán saca a la luz ${ }^{3}$. La escritora gallega

1. Los conceptos "segundo Romanticismo" y "Postromanticismo" siguen la interpretación historiográfica establecida por Russell P. Sebold en "La filosofía de la Ilustración y el nacimiento del Romanticismo español" (especialmente, las páginas 102-105) y en "Introducción: El desconsolado sentir romántico" (en concreto, las páginas 38-40), ambos artículos pertenecientes a Trayectoria del romanticismo español, Barcelona, Crítica, 1983.

2. Pedro Antonio de Alarcón, El Niño de la Bola, Madrid, Imprenta central a cargo de Víctor Saiz, 1880, pág. 6 .

3. La ilustre escritora gallega en varias ocasiones analizó la personalidad y obra del novelista, siempre en términos laudatorios, como - por ejemplo-en los números $9,10,11$ y 13 de su Nuevo teatro crítico (1891-1892), posteriormente reeditado como folleto con el título Pedro Antonio de Alarcón y, en 1908, formando parte de la colección Retratos y apuntes literarios. Este trabajo, junto al estudio que realizara sobre Don Pedro Antonio en La cuestión palpitante, es uno de los más profundos entre los que los contemporáneos del escritor andaluz le dedicaron. 
cree que los personajes de las novelas largas de Don Pedro Antonio (El escándalo, El Niño de la Bola y La pródiga) tienen "filiación romántica", se pregunta si el novelista andaluz no agradará tanto "por conservar aún cierto perfume romántico"', y acaba concluyendo que Alarcón es "el eslabón que enlaza con la actual esa época anterior de la novela española, donde figuran 'Fernán', la Avellaneda, la Coronado, Trueba, Selgas, Fernández y González y Miguel de los Santos Alvárez"6.

En suma, Doña Emilia no dice que nuestro novelista pertenezca al Romanticismo, tan sólo habla de "filiación" y de "cierto perfume romántico", aunque tampoco se atreve a afirmar que Alarcón sea un representante de la "actual" novela española. Esta actitud crítica de la autora gallega convierte a Don Pedro Antonio en "la soldadura de los dos períodos" , el romántico y el realista.

El siglo XX ha aportado también su grano de arena en torno a la definición de El Niño de la Bola y de la manera de novelar de su autor ${ }^{8}$. Quien, en 1955, más páginas dedicó a este tema fue José F. Montesinos en su libro titulado Pedro Antonio de Alarcón. Al inicio de este texto ("Nota Preliminar"), se asienta lo siguiente sobre nuestra novela y su autor:

Siempre fue, quisiéralo o no, un novelista romántico - la mejor novela romántica de nuestra literatura es, posiblemente, El Niño de la Bola-?.

Sin embargo, líneas antes, en la misma "Nota Preliminar", Montesinos había señalado que El escándalo y El Niño de la Bola son "libros en que Alarcón profesa abjurar del romanticismo y en que, por incidir en polémicas que enardecieron su época, hubo de esforzarse por lograr una fórmula artística, que no era ya la de sus mocedades"10.

Momentáneamente da la impresión de que Montesinos acerca a Don Pedro Antonio a las nuevas maneras de pensar y novelísticas realistas, pero se trata de una ilusión, ya que - según el crítico- el novelista andaluz no logra "volver la espalda al romanticismo"ll por culpa de sus lectores, que

4. Emilia Pardo Bazán, La cuestión palpitante, en Cuentos. Crítica literaria (selección), t. III de sus Obras Completas, Madrid, Aguilar, 1973, pág. 639.

5. Ibid.

6. Ibid.

7. Ibid.

8. Destacan, junto al de José F. Montesinos, los trabajos de J.A. Balseiro ("Pedro Antonio de Alarcón", Novelistas españoles modernos, Nueva York, Mac Millan, 1933), de J. Romano (Pedro Antonio de Alarcón, novelista romántico, Madrid, Espasa-Calpe, 1933) o de E. Pardo Canalís (Pedro Antonio de Alarcón, Madrid, Compañía Bibliográfica, 1966), entre otros muchísimos.

9. José F. Montesinos, Pedro Antonio de Alarcón, Zaragoza, Librería General, 1955, s.n.

10. Ibid.

11. Ibíd., pág. 20 
son - todavía- un "romántico público"12. Al final, José F. Montesinos, ante esta ambivalencia romántico-realista de Don Pedro Antonio, propone un nuevo título para su libro: "Mi estudio debería titularse Alarcón en la encrucijada post-romántica"13.

Y en la misma encrucijada en la que lo dejaron Emilia Pardo Bazán y José F. Montesinos continúa en la actualidad Pedro Antonio de Alarcón, ya que - a pesar de que casi todos los críticos del siglo XX lo tildan de romántico (J. A. Balseiro, Ricardo Gullón, Julio Romano, etc.)- las historias de la literatura incluyen al novelista andaluz en los capítulos correspondientes al Postromanticismo o al Realismo, pero - nunca-bajo el epígrafe Romanticismo.

El presente artículo pretende ser una definición de la manera novelística alarconiana; sin embargo, sus conclusiones — desde el reducido campo del estudio de una obra concreta, El Nińo de la Bola- desean cuestionar las fronteras hasta ahora establecidas entre el Romanticismo y el Realismo. Este propósito va a iniciarse con la demostración de la profundidad con que Don Pedro Antonio elaboró su análisis de los caracteres de Manuel Venegas y de la "Dolorosa" (Soledad), continuará con el establecimiento - a través de El Niño de la Bola y de comentarios críticos del período- de lo que en la segunda mitad del siglo XIX se entendía por "novela contemporánea", y concluirá con el intento de negar la barrera que la tradición ha levantado entre la novelística romántica y la del Realismo. De forma indirecta, mi estudio va a poner en evidencia la clarividente interpretación histórica que subyace bajo El Niño de la Bola.

\section{Manuel o la historia clínica del hombre romántico ${ }^{14}$}

Algunos elementos de El Niño de la Bola son muy extraños. Por ejemplo, Alarcón se interesa en hacernos presenciar diversas etapas vitales de la existencia de Manuel Venegas: asistimos a su infancia y educación, le observamos cuando tiene trece ${ }^{15}$, catorce ${ }^{16}$, quince ${ }^{17}$ años, acudimos a su ono-

\section{Ihid.}

13. Ibid, s.n.

14. Una "historia clínica" o "físiología" es el intento de reconstrucción "científica" de un "tipo"o "raza" (personalidad o colectivo social). Desde el siglo XVIII, estos estudios comenzaron a adquirir gran importancia, destacando la relación existente entre el medio/circunstancias y la "psicología" de un individuo, clase o pueblo. Una vez establecida esta inicial conexión bajo la idea de que el medio determina el carácter de una persona o colectividad, se analizaban detenidamente sus efectos y sus implicaciones psicológicas, morales, políticas, o -tan sólo- de naturaleza folklórica.

15. Pedro Antonio de Alarcón, op. cit., pág. 55.

16. Ibíd., pág. 69.

17. Ibid., pág. 72. 
mástica de los dieciséis ${ }^{18}$, a los diecinueve ${ }^{19}$ Manuel parte de viaje hacia Europa y América, y - finalmente-regresa a los veintisiete a la ciudad. Asimismo, parece existir una extraña relación entre el Niño de la Bola y la naturaleza: se educa en ella, cuando el padre de Soledad le rechaza, cura su dolor en el seno de La Alpujarra, para ganar dinero explota todas las riquezas naturales de la montaña andaluza, cuando se entera de que Soledad se ha casado y es madre de un hijo se refugia - otra vez - en dicha sierra y en ella consuela su dolor, y en América se enriquece aprovechando la rica naturaleza del Nuevo Mundo. Por otra parte, Don Pedro Antonio da la impresión de querer reconstruir la historia o génesis de la personalidad de Venegas. Sin lugar a dudas, tomando en consideración los tres aspectos arriba desarrollados, se puede afirmar que El Niño de la Bola está en la órbita de un texto que, en 1762, publicó Jean-Jacques Rousseau con el título de Émile ou de l'éducation.

En las líneas que siguen, pretendo demostrar que a Manuel Venegas, el protagonista de El Niño de la Bola, se le educa siguiendo — de la A a la Z- el programa docente establecido por Rousseau en su tratado educacional. Alarcón desea que se entienda la personalidad del joven Manuel a sus veintisiete años (instante en que se desarrolla la novela) como producto directo de la educación rusoniana. Dicho de otro modo, el Niño de la Bola es un nuevo Emilio "andaluz"20.

El Émile de Jean-Jacques Rousseau está dividido en cinco libros que proponen una metodología docente específica para cada uno de los períodos vitales en el crecimiento del hombre, desde que nace hasta que contrae matrimonio. Las distintas etapas del desarrollo humano según el filósofo francés son las siguientes: a) Libro I: "L'âge de nature" o período del niño de pecho que comprende desde el nacimiento hasta los dos años, b) Libro II: "L'âge de nature" o infancia que abarca de los dos años a los doce, c) Libro III: "L'âge de force" o período de los doce a los quince años, d) Libro IV: "L'âge de raison et des passions" que abarca de los quince años a los veinte, y e) Libro V: "L'âge de sagesse et du mariage" que va de los veinte a los veinticinco años. En cada uno de estos libros se desarrolla el programa específico de actividades docentes propias para el período, dividiendo éstas en diferentes contenidos en consonancia con el momento vital del alumno (por ejemplo, educación moral, intelectual, sensorial, del cuerpo y de la sensibilidad en la etapa de los dos a los doce años, pero educación del ser moral y educación religiosa en "L'âge de raison et des passions", es decir, de los quince a los veinte años, etc.

18. Ibíd., pág. 76 .

19. Ihid., pág. 103.

20. Se comprenderá la gran importancia del adjetivo "andaluz" en la segunda parte de mi trabajo, "La novela contemporánea y el estudio de costumbres", cuando analice el papel que — según los hombres del XIX - jugaba la "raza" o sangre en la determinación psicológico-cultural de un individuo o de una colectividad. 
La vida de Manuel Venegas narrada en El Niño de la Bola se presenta en cuatro etapas muy bien delimitadas cronológicamente y que corresponden -en realidad- a los cinco períodos vitales rusonianos que acabo de especificar:

a) La primera comprende desde el nacimiento del Niño de la Bola hasta el período de los trece años, es decir, abarca lo que en el sistema de Rousseau serían el Libro I o educación para el niño de pecho y el Libro II o infancia. La razón por la que Don Pedro Antonio reunió en uno lo que en el ginebrino eran dos períodos diferentes es obvia: ¿qué interés tiene saber quién amamantó a Manuel? Sin embargo, aun en esto -como veremosnuestro novelista siguió a Jean Jacques Rousseau.

b) El segundo período de la educación de Manuel Venegas comprende desde la edad de trece años hasta los dieciséis, "L'âge de force" del personaje alarconiano.

c) La tercera etapa va de los dieciséis a los veinte años del Niño de la Bola, es decir, ésta es su "âge de raison et des passions".

d) El cuarto y último período abarca de los veinte a los aproximadamente veintisiete años de Manuel y corresponde punto por punto a "L'âge de sagesse et du mariage" del tratado educacional de Rousseau.

Veamos con detención cada uno de los períodos docentes que convierten a nuestro Niño de la Bola en un Emilio rusoniano-andaluz.

Del nacimiento a los dos años. "L'âge de nature ou le nourrisson" de Manuel Venegas.

La madre del Niño de la Bola, se nos dice en la novela, murió cuando éste era muy pequeño. Desde el punto de vista de la nutrición del recién nacido, este hecho no significaba problema alguno ya que en la época los bebés tenían un ama de cría. En la España del momento, ésta era costumbre consagrada. Sin embargo, en el Émile, Rousseau dedica abundantes páginas a desterrar esta tradición, nociva -según él_- para el mantenimiento del calor y de las buenas costumbres en el seno de la familia y para la salud de la psique del pequeño. A Manuel Venegas, como hijo de noble y como hijo de su época, bien le habría correspondido un ama de pecho, pero el filósofo franco-ginebrino puso de moda las mamás lactantes ${ }^{21}$, y al Niño de la Bola

21. Cuento con dos testimonios, uno del siglo XIX y otro del XX, que reconocen la paternidad roussoniana del hecho de que las mujeres nobles de últimos del siglo XVIII e inicios del XIX amamantaran a sus hijos, en lugar de dejarlos a cargo de un ama de cría, según había sido tradición hasta el momento. Doña Emilia Pardo Bazán, hablando sobre Rousseau, dice: "Las mujeres lo idolatraron; las madres lactaron a sus hijos para obedecerle" (La cuestión palpitante, op. cit., pág. 598). En 1914, Miguel S. Oliver (Hojas del sábado. La herencia de Rousseau, Barcelona, Gustavo Gili Editor, 1919), asimismo lo reconoce:

Extasiadas por tal libro [se refiere al Émile], las bellezas del antiguo régimen se ensayaron en las dulzuras del "retorno a la naturaleza". Cuidaron de sus hijos y pusieron en su boca el pezón deformado por largos años de desobediencia a las leyes de la maternidad (pág. 17). 
le amamantó su misma madre. La novela es clara al respecto:

Y hasta hubo alguien que se le presentó a título de hermano de leche, ignorando, sin duda, que el joven fue amamantado por su propia madre ${ }^{22}$ (subrayado de Alarcón).

La madre, en el programa pedagógico del Émile, cumplía únicamente la función de amamantar, y la mamá de Manuel muere una vez efectuado su cometido. El Niño de la Bola - dice la novela - no conoció a su madre.

Para Jean-Jacques Rousseau, el progenitor es "le véritable précepteur"23. En el Libro I del Émile, el principio docente fundamental es el que sigue: la madre debe ser la "véritable nourrice" 24 del niño, pero al padre - aunque éste tenga que abandonar otras obligaciones - le corresponde la educación del pequeño. Manuel Venegas nunca asiste a la escuela:

Otros se denominaron sus condiscípulos... (¡cuándo sabemos que nuestro héroe no había asistido a más escuela que el despacho de D. Trinidad Muley!) ${ }^{25}$ (subrayado de Alarcón).

Manuel tuvo - sin embargo- dos preceptores muy buenos: su padre, Don Rodrigo, y el sacerdote, Don Trinidad.

De los dos años a los trece. "L'âge de nature ou de l'enfance" de Manuel Venegas.

¿Cuál es la educación que Don Rodrigo dio a su hijo? Oigámosla de la misma boca del narrador:

Criábalo D. Rodrigo con el mayor esmero, no cifrado todavía en enseñarle nada literario, ni tan siquiera a leer y a escribir, de lo cual decía que siempre habría tiempo, sino en fortalecer y avalorar su ya robusta naturaleza física, sujetándolo a rudos ejercicios de agilidad y fuerza, aleccionándolo en la equitación y en la natación, obligándolo a andar largas jornadas en interminables cacerías y explicándole de paso los misterios de la Sierra, la botánica de los montesinos, la medicina de los cortijeros, la astronomía de los pastores, las costumbres de todos los animales, la manera de luchar con ellos y matarlos, o de cogerlos vivos y reducirlos a su obediencia, y otros muchos secretos de la vida agreste y montaraz ${ }^{26}$.

Rousseau aconsejaba al preceptor educar a su hijo o pupilo en el cam-

22. Pedro Antonio de Alarcón, op. cit., pág. 235.

23. Jean-Jacques Rousseau, Émile o de l'éducation, Paris, Garnier-Flammarion, 1866, pág. 51.

24. Ibid.

25. Pedro A. de Alarcón, op. cit., pág. 235.

26. Ihíd., pág. 43 . 
po por motivos de salud corporal y de aprendizaje $\mathrm{e}^{27}$. ¿Y qué clase de educación debía impartirle? El filósofo es tajante al respecto: no libros antes de los doce años ${ }^{28}$, tampoco es necesario saber leer $^{29}$ ni escribir ${ }^{30}$ en este período vital, en cambio, debe darse al pequeño una enseñanza práctica ("il prend ses leçons de la nature et non pas des hommes":31), y, sobre todo, se debe hacer gran hincapié en los ejercicios físicos ${ }^{32}$, en los preceptos higiénicos ${ }^{33}$ y en la natación ${ }^{34}$.

Hay otro detalle curioso que no puede tener otro origen que el Émile de Rousseau. Muchas páginas ${ }^{35}$ dedica el filósofo a explicar que, desde la más tierna infancia, debe prohibirse a los niños que lloren y griten. La razón es que los gritos y los lloros son la expresión inicial de los bebés para conseguir sus objetivos, y si se desea un hombre que sepa doblegar sus pasiones, se ha de acabar con el llanto y los gemidos desde temprana edad ${ }^{36}$. Manuel pierde a su padre y relata la novela:

Nadie había hecho caso del infeliz en el primer momento de angustia, ni reparado en que no gemía, hablaba ni lloraba;... iNo había, pues, derramado ni una sola lágrima ${ }^{37}$.

27. Jean-Jacques Rousseau, op. cit, págs. 66, 84-85 y 115-116.

28. Ibíd., pág. 145.

29. Ibid.

30. Ibíd., pág. 146.

31. Ibíd., pág. 149.

32. Ibid., págs. 147 y 150 .

33. Ibíd., págs. 158-166.

34. Ibid., pág. 166.

35. Ibid., págs. 74-80 y 89-102.

36. Los hombres del siglo XIX comprendían perfectamente el origen rusoniano de la ausencia de lloros como producto de una educación peculiar de la sensibilidad y de las pasiones recomendadas por el filósofo francés. Don Jacinto Sarrasí, discípulo del pedagogo Montesino, es una prueba contundente de ello:

Era Virginia, hija de Montesino, niña de excesivo temperamento nervioso, excitable por tanto, y llorona en demasía. El padre, siguiendo los consejos de Rousseau, intentaba curarla de sus desagradables y abundantes lloros, no tomando el menor cuidado por ellos. Y en efecto, púsolo por obra en la primera ocasión que le pareció propicia para el experimento. Al cabo de horas de Ilorar en sitio retirado, calló la niña y el padre creía ya, lleno de gozo, ver confirmadas las indicaciones del autor del Emilio; la niña, sin embargo, había dejado de llorar porque era presa de un síncope, que puso su vida al borde del sepulcro. Desde entonces, según el relato, parece que renegó Montesino no sólo de Rousseau sino de las doctrinas pedagógicas de allende el Pirineo, y que en tal sentido hablaba a sus discípulos cuando los veía aficionados a ellas. (J. Sama, Montesino y sus doctrinas pedagógicas, Barcelona, Librería de Juan y Antonio Bastinos, 1888, págs. 15-16).

37. Pedro Antonio de Alarcón, op. cit., pág. 50. 
Las coincidencias del Émile con el programa educacional seguido desde el nacimiento de Manuel son extraordinarias. Una más. Rousseau concibe al padre como el verdadero preceptor de su hijo, pero -dado que la nobleza a menudo está demasiado ocupada para cumplir con este deber fundamental - el filósofo, extremando la importancia de la buena elección de un preceptor-no padre, convierte, en su hipótesis teórica educacional, a su pupilo en un niño huérfano ${ }^{38}$ aunque sus padres siguen viviendo; Emilio no será educado por su progenitor, sino por un maestro extraño. Manuel Venegas, muy pronto huérfano de madre, pierde también a su padre a la edad de diez años, y en ese mismo momento pasa a depender de un tercer personaje, Don Trinidad Muley.

De los doce a los quince años. "L'âge de force" de Manuel Venegas.

Llegados a este punto, el Niño de la Bola ha perdido a su padre y ganado un nuevo preceptor. ¿Cambiará ahora su educación? Uno de los consejos que el filósofo franco-ginebrino da repetidamente es que no se inculque al pupilo prejuicio religioso alguno. Don Trinidad Muley, el nuevo padre de Manuel, es un sacerdote y un buen cristiano. ¿Traicionará a Rousseau?

No. Pedro Antonio de Alarcón ofrece una imagen del cura bastante afín a lo rusoniano: Don Trinidad prefiere la vida del campo a la civilización $^{39}$, a Don Trinidad le sobran también los libros ${ }^{40}$, y finalmente tampoco el buen sacerdote tiene prejuicios religiosos:

El ejemplar que tenemos a la vista era al propio tiempo tan natural y sencillo de suyo [...] que lo mismo que servía para cura párroco de Santa María de la Cabeza [...] hubiera servido para sacerdote hebreo, mahometano, protestante o chino, con gran respeto y edificación de tales gentes ${ }^{41}$.

Según la descripción que Don Pedro Antonio da de Don Trinidad, éste bien puede educar al joven Venegas en una especie de deísmo y de religión por los sentidos, semejante al tipo de religiosidad con la que le había instruido hasta el momento su padre, Don Rodrigo Venegas ${ }^{42}$. Así pues, ha cambiado el nombre del preceptor, pero no cambiará la pedagogía.

Nos encontramos en el Libro III del Émile. El punto más innovador que se incluye en "L'âge de force" (de los doce a los quince años) es la adquisi-

38. Jean-Jacques Rousseau, op. cit., pág. 57.

39. Pedro Antonio de Alarcón, op. cit., pág. 70.

40. Ibíd., pág. 48.

41. Ihíd., págs. 46-47.

42. Para observar el carácter de los principios "religiosos" inculcados por D. Rodrigo, véase ibíd., pág. 53. 
ción por parte del pequeño del arte de la supervivencia y de la utilidad ${ }^{43}$. Emilio debe tener pocos conocimientos (ninguno libresco), pero éstos han de ser verdaderamente suyos y —más importante- útiles; quizás ésta sea la razón por la que Rousseau, quien hasta el momento no había permitido educación literaria alguna a su pupilo, ahora le lee un texto muy peculiar, Robinson Crusoe de Daniel Defoe ${ }^{44}$.

Pasando a El Niño de la Bola, nuestro protagonista responde de nuevo al modelo rusoniano. A la edad de catorce años y hasta los dieciséis, Manuel "comenzó a emprender largas excursiones a la Sierra"45. Allí se estaba días seguidos y meses enteros sin provisiones, comiendo "frutas bordes, y legumbres salvajes, y muchas caza mayor y menor"46, que cazaba con "una honda de cáñamo,... iy con ramas de árbol! ¡y a brazo partido! ¡y a bocados, si es menester!" 47 . Además no sólo alimento consigue el joven en estas cacerías, sino que cubre con ellas otras necesidades básicas: "y siempre vestido con pieles de sus adversarios" ${ }^{\prime 4}$. Sin duda, Manuel Venegas posee un pleno sentido de lo útil y de su supervivencia ${ }^{49}$.

De los quince a los veinte años. "L'âge de raison et des passions" del Niño de la Bola.

Emilio posee ya, según Jean-Jacques, una plena conciencia de utilidad. Ahora debe aplicar a ella su razón para desplegarla al máximo, es así como en este nuevo período de su vida se espera del joven huérfano que aprenda a construir máquinas y artimañas que le permitan una total victoria sobre la naturaleza. También Rousseau cree necesaria en esta etapa de la vida de su pupilo una pequeña educación social, acompañada de los principios sexuales y religiosos básicos (que ordenen el ímpetu que las pasiones comienzan a tener en la vida del joven), y la elección de un empleo por parte de Emilio.

El día que Manuel Venegas cumple 16 años, es decir, en el momento en que pasa de "l'âge de force" a "l'âge de raison et des passions", el joven toma tres decisiones fundamentales para su vida. Una decisión tiene que ver consigo mismo: decide trabajar para ganar dinero ${ }^{50}$. La segunda decisión tiene que ver con la gente de su ciudad: su plan social es ir bien vestido y "hacer justicia"51 ("destronar matones", "reprimir déspotas", "defender a

43. Jean-Jacques Rousseau, op. cit., págs. 215-240.

44. Ibid., pág. 239.

45. Pedro Antonio de Alarcón. op. cit., pág. 70.

46. Ibid.

47. lbíd.

48. Ibíd., pág. 71.

49. Véase en el próximo apartado ("De los quince a los veinte años") la intención literaria que tuvo Don Pedro Antonio al dibujar con tales atributos a nuestro personaje.

50. Pedro Antonio de Alarcón, op. cit., pág. 95.

51. Ibíd., pág. 100 . 
los débiles contra los fuertes" y "corregir todo abuso, toda iniquidad, toda tropelía que trajese indignados a los hombres de bien" ${ }^{2}$ ). La última decisión es respecto a Soledad: va a verla una única vez por semana, en la Iglesia, pero ello será suficiente para crear a su alrededor un vacío que la convierta en suya, evitando que nadie se la dispute.

Recordemos una vez más. Rousseau hablaba en "l'âge de raison et des passions" de elección de un empleo, de educación social y de la necesidad de dictar principios religiosos y sexuales básicos. Las tres decisiones que Manuel Venegas toma en su décimosexto cumpleaños son la expresión literaria alarconiana de los puntos pedagógicos de Jean-Jacques en este período. Todo se cumple paso por paso para que el Niño de la Bola se convierta en un nuevo Emilio, porque, al igual que al huérfano rusoniano le habla de religión y de comportamiento sexual el "vicaire savoyard" (el vicario saboyano $)^{53}$ y el propio preceptor ${ }^{54}$ respectivamente, a Manuel le va a discursear sobre los mismos temas Don Trinidad Muley, discurriendo "la manera de conciliar con los eternos principios de la moral y de la justicia el cariño de Manuel a Soledad" 55 .

Me interesa, sin embargo, desarrollar uno de los puntos de la teoría docente rusoniana en "l'âge de raison et des passions": la utilización del raciocinio en pro del principio de lo útil.

Industrias allí olvidadas desde la expulsión de los Moriscos, o en desuso desde la muerte de D. Carlos III, y no pocos provechos y explotaciones que hasta época recientísima no han merecido la atención de las gentes, sirvieron de objeto a la pasmosa inventiva y titánica laboriosidad de Manuel, el cual, sin ayuda ajena, por no divulgar secretos que poseía él solo, fue juntamente herbolario, cazador con destino a la peletería, maderero de especies extrañas y preciosas, colector de bichos raros, cantero de jaspes y de serpentina, y lavador de oro $^{56}$.

-Desvió, pues, las aguas de sus cauces, construyó presas y balsas, condensó por decantación las hojuelas y pajitas de oro, como hoy se hace en la California...-Y, para conducir rodando, sin que se quebrasen, hasta el pie de la Sierra los jaspes y la serpentina, forró de grandes hierbas y de bien trabado ramaje sus pesadas moles, y las deslizó, a riesgo de morir, por las chorreras de las nieves derretidas ${ }^{57}$.

52. Ibid.

53. Jean-Jacques Rousseau, op. cit., págs. 345-410.

54. Ibíd., págs. 273-286.

55. Pedro Antonio de Alarcón, op. cit., pág. 73.

56. Ibíd., pág. 96.

57. lbid., págs. 87-88. 
Las citas son extensas, pero necesarias para presentar la imagen que Don Pedro Antonio dibuja de Manuel: un hombre enfrentado -él solo- a la naturaleza y venciéndola a través de las máquinas y artimañas que su razón y su sentido práctico le permiten construir. ¿Recuerda esta imagen a alguna otra figura literaria? A Leopoldo Alas sí se la recordó. El "ovetense universal", en su artículo titulado "El Niño de la Bola (Alarcón)", reconocía claramente la filiación de la figura de Manuel Venegas:

El Niño de la Bola, Venegas, es una mezcla inverosímil y desmañada de Gilliat, Robinsón y contrabandista ${ }^{58}$ (subrayado mío).

Leopoldo Alas había leído muy bien a Don Pedro Antonio cuando éste escribió sobre su personaje: "tuvo que ser... un Titán semejante al prodigioso Gilliat de Victor Hugo"59 (subrayado mío). También al inicio de su novela, Alarcón había sugerido que el enigmático hombre que recorre la Sierra hacia la ciudad "parecía juntamente un feriante, un contrabandista y un indiano" ${ }^{6()}$ (subrayado mío). Es decir, el mismo autor andaluz identificó explícitamente a Manuel con Gilliat de Victor Hugo y con un contrabandista, pero nunca menciona en El Niño de la Bola a Robinsón Crusoe. La analogía entre éste y el joven Venegas ${ }^{61}$ - sin embargo-está ampliamente desarro$\operatorname{llada}^{62}$, de manera que Leopoldo Alas —aun sin comprender el alcance de su descubrimiento - se da cuenta de la relación existente entre el personaje de Daniel Defoe y el de Don Pedro Antonio. La profundidad de la naturaleza crusoniana de Manuel Venegas se hace evidente cuando se recuerda que la única lectura que Rousseau permitía a su pupilo de los doce a los quince años ("l'âge de force") era Robinson Crusoe. ¿Por qué Alarcón establece esta línea identificativa entre el texto de Defoe, el de Rousseau y su El Niño de

58. Leopoldo Alas, "El Niño de la Bola (Alarcón)", Solos de Clarín, Madrid, Alianza, Libro de Bolsillo, n?350, 1971, pág. 217.

59. Pedro Antonio de Alarcón, op. cit., págs. 98-99.

60. Ibíd., pág. 10.

61. La imagen que de Manuel da Don Pedro Antonio corresponde a la de Robinsón, pero Don Juan Valcra me inspira anotar la posibilidad de que exista alguna conexión entre el personaje del autor andaluz. (nació en Guadix) y el portagonista de una novela árabe que "la escribió un mahometano natural de Guadix, que vivió en el siglo XII de nuestra Era y que tenía por nombre Abubequer Abentofail", ("El filósofo autodidacto", Crítica literaria. Estudios críticos. Historia y politica. Miscelánea, volumen 2 de las Obras Completas, Madrid, Aguilar, 1942, pág. 1023). La semejanza entre el protagonista de El Niño de la Bola y el de El filósofo autodidacto radica en que ambos logran vencer a la naturaleza a través de su sentido de la utilidad y de su razón. Por otra parte, si el mismo Don Juan Valera está en lo cierto, parece existir cierta línea de continuidad e influencia entre la novela árabe y la obra de Defoe:

Las aventuras de Robinson Crusoe, que tanto nos han embelesado a todos cuando niños, y cuya lectura nos deleita aún, bien podemos jactarnos de que, hasta cierto punto, han sido inspiradas por la obra del antiguo novelista de Guadix (lbid.).

62. Pedro Antonio de Alarcón, op. cit., págs. 70-71 y 96-99. 
la Bola? Robinson significaba en el siglo XVIII ${ }^{63}$ la imagen prototípica e ideal del hombre que, guiado únicamente por la Razón y por un sentido práctico de la utilidad, conseguía sobrevivir y vencer -él solo- a la naturaleza. Este mismo era el objetivo deseado por Jean-Jacques Rousseau en el período vital de "l'âge de raison et des passions": un individuo autosuficiente en su lucha por la vida. Por otra parte, Don Pedro Antonio, siguiendo punto por punto el manual pedagógico del filósofo franco-ginebrino, convierte a Manuel Venegas en un nuevo Robinsón porque a ello le arrastraba una lectura atenta del Émile.

De los veinte a los veinticinco años. "L'âge de la sagesse et du mariage" de Manuel Venegas.

El pupilo de Rousseau terminaba la etapa educacional precedente con la conciencia de que lo único que necesitaba antes de contraer matrimonio era adquirir una buena cantidad de dinero. No otra es la razón por la que Manuel Venegas parte de su tierra natal: su difunto padre todavía debe un millón de reales al viejo usurero, éste se lo reclama, y Manuel está dispuesto a conseguirlo con creces y pagar a "Caifás". Habrá, pues, una separación entre Soledad y su enamorado, pero incluso este distanciamiento está presente ya en el texto de Rousseau: Emilio - asimismo- ama a una joven, pero su preceptor le aconseja partir de viaje en busca, no sólo de dinero, sino también de un mejor conocimiento de los pueblos y de la política del mundo.

Manuel recorre muchos países, llegando incluso a América, en donde, gracias a la exuberante naturaleza del Nuevo Mundo, consigue nuestro EmilioRobinsón andaluz la riqueza deseada; sin embargo, de sus viajes, Manuel Venegas llega cargado con otro bagaje: el Niño de la Bola regresa librepensador, ateo y convertido en una personalidad totalmente romántica. Éste - según Don Pedro Antonio- es el fruto de unos viajes prematrimoniales que, en la mente e intenciones de Rousseau, iban destinados a una mejor comprensión de las costumbres y de la política de otros pueblos.

El romanticismo del carácter del joven Venegas es - de los tres aspectos antes mencionados (librepensamiento, ateísmo y romanticismo) - el que Alarcón desarrolla en la novela. Relata con todo detalle el pasado de su personaje para afirmar que él es la causa de su presente, dicho de otro modo, que el "rusonismo" de la infancia y juventud de Manuel Venegas

63. El protagonista del libro de Defoe de tal manera representaba el ideal de hombre de la Ilustración que - en nuestra Península - uno de los máximos eruditos, Don Tomás de Iriarte, tradujo al castellano un texto de Heinrich Campe sobre este personaje, con el título de El nuevo Robinsón, historia moral. reducida a diálogos para instrucción y entretenimiento de niños y jóvenes de ambos sexos (Madrid, Imp. de Cano, 1789). A juzgar por el número de ediciones que contabiliza José F. Montesinos (Introductión a una historia de la novela en España en el siglo XIX, Madrid, Castalia, 1982), catorce en concreto desde 1800 hasta 1850 de El nuevo Robinsón y más de seis de las Aventuras de Robinsón Crusoe en el espacio de quince años (1835-1850), la figurá del héroe de Daniel Defoe contó con una gran aceptación, no sólo en el período ilustrado, sino también en la primera mitad del siglo XIX. 
determina la personalidad romántica de su madurez ${ }^{64}$. Para Don Pedro Antonio, hay un salto que comunica - de manera directa- a Rousseau con el Romanticismo ${ }^{65}$.

Cuando la novela se inicia, el Niño de la Bola tiene veintisiete años. La primera imagen que de él ofrece Alarcón es propiamente romántica. En medio de una naturaleza salvaje, Sierra Morena, surge un individuo que "parecía juntamente un feriante, un contrabandista y un indiano. También hubiera sido fácil suponerlo un capitán de bandidos de primera clase"

Sea bandido, contrabandista, feriante o indiano, los cuatro son modelos de héroes marginales del Romanticismo; la aureola de misterio en que se envuelve la figura de Venegas en las veinte páginas inicales de la obra confirma también la intención alarconiana de caracterizar al protagonista de la novela como una personalidad romántica.

Después de esta primera presentación, el narrador va acercando su cámara para describirnos la apariencia física y moral del individuo. Nuevamente, la semántica del romanticismo hace entrada: "triste" 67 , "selvática melancolía"68, "grandeza de alma"69" "ardientes ojos"70, etc.

El resto de la obra no hace más que incidir cada vez con mayor profundidad en la naturaleza escindida y ambivalente de los héroes románticos:

64. En un próximo estudio demostraré cómo - para Alarcón- la psique romántica de sus personajes (Fabián Conde en El escándalo, Manuel Venegas y Doña Luisita en El Niño de la Bola y la protagonista de La pródiga) se presenta siempre como producto de una educación rusoniana. El novelista andaluz interpretó de igual manera las personalidades románticas de su época, como — por ejemploLord Byron, Edgar Allan Poe o Napoleón, lo que indica que Don Pedro Antonio fue consciente del papel determinante que jugó Rousseau en la nueva atmósfera mental de las últimas décadas del siglo XVIII y en la primera mitad del XIX.

65. La nueva atmósfera mental a la que aludí en la anterior cita y su dependencia directa del filósofo franco-ginebrino es un lugar común cultural de la crítica contemporánea. Al respecto, pueden nombrarse algunos de sus máximos defensores: Marcelino Menéndez Pelayo (Historia de las ideas estéticas en España, Santander, C.S.I.C.-Aldus, 1917), Miguel S. Oliver (en op. cit.), Irving Babbit (Rousseau and Romanticism, Boston, Houghton Mifflin Company, 1919), Juan Miguel Bargallo Cirio (Rousseau. Elestado de la naturaleza y el romanticismo político, Buenos Aires, Librería Jurídica, 1952), etc.

Aquellos que estén interesados en la influencia concreta de Jean-Jacqques Rousseau en España pueden consultar los diferentes trabajos de Jefferson R. Spell ("Pigmalion in Spain", Romanic Review, 2, 1934, págs 395-4o1; "Rousseau's 1750 Discourse in Spain”, Hispanic Review, 2, 1934, págs 334-344; "A Tentative Bibliography of Spanish Traslations of the Works of Rousseau", Hispanic Review, 2, 1934, págs. 134-152; Rousseau in the Spanish World before 1833, Austin, University of Texas, 1938; y el artículo sobre el mismo tema de Angel del Río ("Algunas notas sobre Rousseau en España", Hispania, 19, 1936, págs. 105-116).

66. Pedro Antonio de Alarcón, op. cit., pág. 10.

67. Ibíd., pág. 12.

68. Ibid.

69. Ibid., pág. 13.

70. Ibid. 
Esta mirada reunía a un mismo tiempo la temible majestad de la del león, la fiereza de la del águila y la inocencia de la del niño ${ }^{71}$.

La novela anota también otro de los caracteres de este tipo de héroe, su lucha interior entre opuestos inconciliables:

De vez en cuando se paraba, e ininteligibles monosílabos, rugidos sordos o sofocados lamentos salían de sus labios, como si dentro de él mantuviesen empeñada controversia dos seres distintos, el uno más feroz que el otro... ${ }^{72}$.

Y otros detalles, que tan sólo mencionaré, reinciden en el dibujo o perfil de Manuel Venegas como una psicología romántica: se siente abandonado por Dios y por los hombres ${ }^{73}$, idolatra a la mujer (a la que adora como su verdadero y único dios):

Para Manuel Venegas no habrá más mujer, ni más dicha, ni más cielo que Soledad [...] - Yo, ni antes de consagrar mi alma a Soledad (y se la consagré a los trece años), ni después de aquel día, ni en esta Ciudad, ni en la ausencia, le he faltado ni con el pensamiento... ¡También he sido yo fiel a mi religión! ¡También he sabido cumplir mis votos! $!^{74}$ (subrayado del autor).

Concibe su sentimiento amoroso como una pasión abrasadora y absorbente de todo su $\operatorname{ser}^{75}$, y le arrastra un destino fatal ${ }^{76}$.

Los síntomas románticos del Niño de la Bola se manifiestan tan intensamente que Don Trinidad Muley los reconoce en su pupilo muchísimo antes de que éste haya conformado su personalidad de hombre adulto: "Tú hablas como los libros prohibidos, sin que nadie te haya enseñado!"77. A sus dieciséis primaveras, Manuel afirma que su amor es el "furor de los huracanes desencadenados" "78, su corazón es de Soledad "como la piedra es del suelo"79, y pedirle que se olvide de su amada es "pedirme toda la sangre de mis venas" $"$. Con tales términos, es lógico que el tutor expresara su preo-

71. Ibíd., pág. 12.

72. Ibíd., pág. 301.

73. Ibíd., pág. 276.

74. Ibíd., pág. 277.

75. lbíd., pág. 72.

76. Ibíd., pág. 264.

77. Ibíd., pág. 91.

78. Ibid.

79. Ibid.

80. Ibid. 
cupación ante la fiebre "romancesca" que padecía su pupilo. Este rasgo enfermizo de la niñez se desarrollará paso a paso hasta concluir en la coherente psicología romántica que he descrito momentos antes. Gracias al pincel maestro de Don Pedro Antonio de Alarcón, su estudio sobre la personalidad del Niño de la Bola se convierte en un historial clínico resumen del origen, desarrollo, proceso y fisonomía de un carácter romántico.

\section{Soledad o la historia clínica de la mujer adúltera}

Si Don Pedro Antonio había creado el personaje de Manuel Venegas a partir del principio de que las circunstancias ambientales vividas durante la infancia y la juventud condicionan la personalidad del individuo en su madurez, no otra va a ser la idea que rige la elaboración de la persona de la "Dolorosa". En el caso del Niño de la Bola, el novelista concibe su psicología romántica, su liberalismo político y su ateísmo religioso como causas directas de la influencia docente de Rousseau; en manos de Alarcón, la psique de Soledad la aboca al adulterio también determinada por las circunstancias vitales de su niñez.

En torno a la protagonista de El Niño de la Bola existe toda una narración de la génesis e historia de su carácter: la "Dolorosa" fue hija mimada, se convirtió en hipócrita y soberbia, y — si su muerte no lo impidierahubiese terminado como esposa adúltera. El desarrollo de este proceso psíquico por parte de Don Pedro Antonio convierte a Soledad en uno de los personajes más profundos, coherentes y sólidos de la novela.

Dos son las circunstancias infantiles que marcan ya para siempre la personalidad de la hija de Don Elías; éstas son: el fuerte carácter de su padre (en especial, el trato que dispensa a su esposa, la señá María Josefa), y el exceso de mimo con que éste halaga a su hija.

Que Soledad es una pequeña mimada es un rasgo que reconocen casi todos los personajes de la novela. Cuando al viejo usurero se le quema su casa y todas las posesiones que en ella tenía, olvida las urgentes necesidades de su misma persona y las de su esposa, pero gasta para su hija "cinco mil duros en ropas, alhajas y juguetes" pequeña posee en un puño la voluntad de Don Elías: "pues ella hará que su padre le diga amén a todo, según costumbre..." incluso el mismo narrador reitera de propia palabra este rasgo de la educación de la muchacha: "En fin..., Soledad, la niña mimada, la hija querida de Caifás" $"$. Del mismo modo, en la novela se expresa una y otra vez que, si Soledad recibe todo el mimo por parte de Don Elías, su madre no es más que el receptor de insultos y desprecio por parte de éste:

81. Ibíd., pág. 41.

82. Ibíd., pág. 78.

83. Ibid., pág. 42. 
Detestando y gruñendo a la buena mujer, antigua criada suya, con quien estaba casado, y acariciando y cubriendo de perlas y brillantes a una preciosa hija (ya de ocho años) que había tenido a la vejez, y a la cual adoraba con sus 5 sentidos y 3 potencias, o sea con lo que en otros hombres se llama alma ${ }^{84}$.

Esta situación familiar va formando la personalidad de la "Dolorosa". Observa la muchacha el mal trato de que es objeto su madre y no lo desea para su persona. Se da cuenta de que, en el caso de contrariar a su progenitor, ella puede perder su agasajo en oro y su tranquilidad en el seno de la familia, "y porque le gusta su papel de niña mimada, no le lleva la contraria a su padre" ${ }^{\circ 5}$. Así se convierte en una perfecta hipócrita y en una soberbia: echa mano de su fuerza de voluntad para vencer sus sentimientos y necesita de la hipocresía para cubrirlos y no hacerlos evidentes. Muchos - en la novela - reconocen este carácter de Soledad: el narrador la califica de "taimada joven" $"$, Luisita (la invitada madrileña de Don Trajano, personaje muy importante en este artículo en el futuro) señala que la "Dolorosa" "tiene una expresión hipócrita que da miedo"87, e incluso su mismo padre la llama: "¡Ah, gran hipócrita!" 88 . En cuanto a su capacidad para ocultar sus sentimientos y deseos, la propia madre de la protagonista la desentraña con estas palabras: "pone todo su orgullo en no descubrir sus aficiones de ningún género y no le gusta comprometerse a nada ni con nadie" 89 .

Otro resultado psicológico fruto de las cirsunstancias familiares vividas por Soledad durante su niñez y juventud es que la joven, en su madurez, acaba siendo un nuevo "Caifás" femenino. Ambos, padre e hija, serán igual de tercos: Don Elías no se deja morir porque no ha arrancado de su hija la promesa de no casarse con Manuel, Soledad acepta su retiro en un convento por no dar dicha promesa a su padre; la tozudez de Don Elías y de

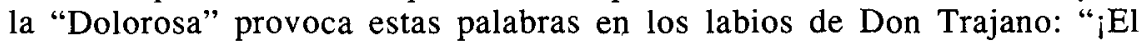
padre y la hija están cortados por una misma tijera!"90. Ambos serán también igual de soberbios. Ante un Niño de la Bola airado y dispuesto a matarlos, ni Soledad ni "Caifás" hacen el mínimo movimiento de huida ni tan siquiera de temor ${ }^{91}$. Ambos, también, padre e hija, tratarán con el mismo desprecio a su esposa y madre:

84. Ibíd., pág. 34.

85. Ibíd., pág. 180 .

86. lbíd., pág. 182.

87. Ibíd., pág. 230.

88. Ibíd., pág. 182.

89. Ibíd., pág. 180.

90. Ihíd., pág. 183.

91. Ibíd., págs., 115, 122 y 241 . 
Sólo la madre (a quien la joven trataba con el mismo despego y poca confianza que el riojano, cual si tampoco perdonase el haber servido honradamente en calidad de criada al que seguía sirviendo humildísimamente en calidad de consorte) $)^{92}$.

Dado el contexto familiar en que vivió y vive la hija de Don Elías, sólo una buena educación escolar hubiera podido favorecer el que la "Dolorosa" superase la psicología arriba descrita y que le determinaba su hábitat. Sin embargo, Soledad pasa su niñez en una "vetusta" 93 urbe de Andalucía por los años que van de 1815 a 1834 , aproximadamente. ¿Qué tipo de enseñanza escolar pudo recibir la pequeña? Un contemporáneo real de la "Dolorosa", llamado Montesino, nos la resume con las siguientes palabras, recuperadas para nosotros gracias al estudio de J. Sama Montesino y sus doctrinas pedagógicas (1888):

Se cuida por lo común de agitar o educar sus dedos para la costura, y algo se ejercitan los sentidos corporales, mas poco o nada absolutamente la razón. Algunas aprenden maquinalmente a leer, y pocas, muy pocas a escribir, porque a este punto no suele llegar la instrucción de la maestra ${ }^{94}$.

Sabemos que Soledad es una de esas pocas afortunadas que llegaron a saber escribir ya que al final de la novela redacta una carta. Pero, según Don Pedro Antonio nos expresa fielmente, la educación recibida por la "Dolorosa" en el "Colegio de Niñas"95 es idéntica a la descrita por Montesino: "donde vulgarísimas muchachas y estólidas maestras... tenían la gloria de verla coser y de oírla decorar sus lecciones"

Con tales instrumentos intelectuales, la joven se hallaba irremisiblemente abandonada a su determinismo familiar, tal como - frente a la incomprensión de la romántica Luisita madrileña - entiende muy bien el moratiniano Marqués de Mirabel:

Pero la hija del usurero no nació para heroína; no nació para defenderse por sí propia: nació para que otros la defendieran o la conquis$\operatorname{taran}^{97}$.

Otro aspecto me interesa en relación a la figura de Soledad: Manuel Venegas es presentado como una psique romántica: exteriomente se le ca-

92. Ibíd., pág. 179.

93. lbíd., pág. 5.

94. Ibíd., pág. 123.

95. Ibíd., págs. 63 y 80.

96. Ibíd., pág. 85.

97. Ibíd., pág. 192. 
racteriza como tal, actúa según este código de comportamiento, y todos sus paisanos -incluyendo su tutor, Don Trinidad Muley ${ }^{98}$ - reconocen la filiación de su carácter. Pero, ¿y la "Dolorosa"? ¿Es ella una personalidad romántica?

La hija de Don Elías apenas habla y apenas actúa a lo largo de toda la novela. Por sí misma no sabemos cómo es. Leopoldo Alas, con su usual clarividencia, lo notó en su artículo sobre El Niño de la Bola, diciendo: "El

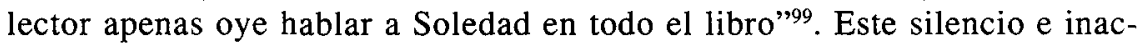
ción de la "Dolorosa" es un recurso más para intensificar el hálito misterioso de una personalidad romántica, técnica también utilizada en los capítulos inciales de la novela con Manuel y utilizada, por ejemplo, con éxito por José de Espronceda en la presentación de Don Félix de Montemar en El estudiante de Salamanca $(1836-1840)^{100}$. ¿Quiere ello decir que Soledad es una heroína romántica?

Si la joven no habla, por lo menos los otros personajes nos cuentan sobre ella. Manuel es el primero que la describe: su percepción es -naturalmente- romántica. Con él participa el pueblo entero, quien ve a la moza como una de las heroínas de la literatura de la época. El narrador, por su parte, no es tan claro en su opinión. Diríase que - desde el principiopretende mantener ambiguo el carácter de la "Dolorosa". La ve románticamente y así la llama "ángel"101, pero a la vez la denomina "la Eva de 12 años"102 o "Dalila" 103 , sugiriendo cierto lado perverso en la joven desde su más tierna edad. Quien de forma determinante niega la naturaleza romántica de la hija de Don Elías es el alienista y moratiniano Marqués de Mirabel $^{104}$. Para Don Trajano, Soledad no es más que un individuo forjado por las circunstacias ambientales en que ha vivido. Los "estudios" de "fisiología" y de "psicología" que realiza sobre ella le demuestran el talante frío, calculador y materialista de la "Dolorosa"; incluso descubre el viejo Marqués cómo el adulterio es la intención última de la muchacha. Leopoldo Alas, leyendo e interpretando los análisis clínicos del seguidor de Moratín, comprende el alcance de las intenciones de la heroína de la novela y las resume así:

98. Ibíd., pág. 91.

99. Leopoldo Alas, op. cit., pág. 221.

100. Russell P. Sebold analizó pormenorizadamente en su artículo: "El infernal arcano de Félix de Montemar" (Trayectoria del Romanticismo español, Barcelona, Crítica, 1983, págs. 195-214) la significación de esta técnica en El estudiante de Salamanca de José de Espronceda.

101. Pedro Antonio de Alarcón, op. cit., pág. 64.

102. Ibíd., pág. 66.

103. Ibíd., pág. 67.

104 Ibíd., pág. 180. 
Soledad, en ausencia de Manuel, tuvo que habérselas con su padre, terrible enemigo a quien no era posible atacar de frente, sobre todo si se quería salvar, además de los principios, las colonias, o sean los diamantes y encajes de que va hecha mención. He aquí el expediente de Soledad: a su padre le da un año de vida; este año lo pasará ella en el convento, si su padre muere entre tanto, ella es libre; pero su padre pasa el año. Ella, antes que profesar, se casa con quien el tirano diga, porque profanar el tálamo es más fácil que profanar el claustro, y Venegas, cuando vuelva, no necesitará saltar las tapias de un monasterio para llegar al logro de sus deseos. Éste es el plan de la Doloro$\mathrm{sa}^{105}$.

Naturalmente, la carta que la hija de Don Elías escribe a Manuel al final de la novela confirma la historia clínica que Don Trajano realizara, destruyendo toda posibilidad de interpretar a la joven como una psique romántica. El Marqués de Mirabel estaba en lo cierto y sus análisis, si no definen a la "Dolorosa" como una heroína del Romanticismo, sí terminan siendo un perfecto estudio del origen, desarrollo y evolución psicológica de una personalidad adúltera.

105. Leopoldo Alas, op. cit., págs. 220-221. 